\title{
THE TRIPOD APPROACH: A PEDAGOGICAL TOOL FOR CONCEPT DEVELOPMENT IN FASHION AND TEXTILE DESIGN
}

\author{
Anne Louise BANG ${ }^{1}$, Eva KAPPEL ${ }^{2}$ and Maria HØGH-MIKKELSEN ${ }^{2}$ \\ ${ }^{1}$ VIA University College, Denmark \\ ${ }^{2}$ Design School Kolding, Denmark
}

\begin{abstract}
In this paper, we discuss ways in which to further develop the pedagogical application of the Tripod Approach, which is a framework originally developed for analysing and designing interior textiles. At Design School Kolding in Denmark, we have used it for over eight years when introducing second year bachelor fashion and textile design students to concept development. Reviewing a selection of the student concepts, we have identified some didactic and pedagogical challenges in relation to exploring the full potential of the framework. The main contribution of this paper is to demonstrate the impact of the pedagogical approach of applying a design framework for concept development in fashion and textile design. Basically, The Tripod Approach suggests considering the visual distance to the object as well as the character of the perception in an overall context. The distance can be divided into three perspectives - material, object and environment - which embrace the multiple levels from fibre to finished product within an overall context. The character of the perception can be either participant or observant. We point to three specific aspects of the framework that may benefit from an adjusted pedagogical approach. These include the students' approach to the overall context, the starting point for concept development and the participant/observant perspective. We conclude the paper linking concept development with experimentation. We argue that the suggested improvements of approaching the framework will have a higher impact on the concept development if the students deliberately can apply different types of experiments to their work.
\end{abstract}

Keywords: Design approach, fashion and textile design, experiments, concept development

\section{INTRODUCTION}

Fashion and textile teaching have changed radically during the past 20 years. Education is often rooted in arts and crafts with the focus on skills and mastering a craft from idea to finished product. As a result of the political, societal and industrial development, most of the schools have changed direction, and their focus is now on design rather than craft. The main goal is to provide students with skills and expertise that meet the demands of the industry and SMEs as well as prepare them to work innovatively, entrepreneurially, cross-disciplinarily and with a social-minded and responsible mindset. This change of focus has demanded major revisions of the curricula, incorporating subject areas such as design process, methodology and theory as well as skills in cross-disciplinary collaboration, communication, etc. It has caused an extensive transformation of the way in which we approach basic disciplinary skills such as weaving, knitting, printing, sewing and pattern construction in our teaching. Basically, it means that instead of training the students as craftsmen mastering a complete skillset within their subject area, we educate them in using tools and techniques for prototyping within different contexts and applications. In parallel with this development, we have access to complex digital tools and applications. This is an asset for our teaching as they support the above-mentioned approach to teaching and education. Obviously, such radical changes of curricula and access to complex digital tools have caused a demand for new approaches to teaching and didactics. In 2003, we introduced the first version of a teaching tool for analysing and designing textiles taking these changes and demands into consideration [1].

The Tripod Approach is a further development of the original teaching tool [1]. Since 2012, we have introduced it in a concept development course for second year bachelor fashion and textile design students at Design School Kolding in Denmark. The concept development course includes an 
introduction to complex digital tools and techniques. With a design concept as the starting point, we urge the students to move beyond merely operating the tools/managing the techniques, e.g. the jacquard loom or 3D fashion design software. With a brief introduction, we didactically encourage them to explore the tools and techniques for further design development instead of teaching technique from AZ. In this way, the students learn to adopt the skills and technique appropriate for a specific concept. Depending on the subject area, the output is a series of textile samples or a line-up of fashion silhouettes. The Tripod Approach frames concept development in a way that ensures that the students have a holistic view on designing. Even if they are focused on fabrics or garments, the design concepts request them to consider the choice of materials as well as a specific application and a broader context. Our experience after eight courses shows that The Tripod Approach provides some help to students in this process. However, we have identified some challenges exploiting the full potential of the framework for designing. Therefore, we specifically discuss the didactic and pedagogical approach to using the framework for designing in this paper.

In the following sections, we introduce The Tripod Approach and briefly present two student concepts to identify the possibilities for improving teaching. This is followed by a discussion suggesting ways in which to alter the pedagogical/didactic approach to the framework. We conclude the paper linking concept development with experimentation. We argue that the suggested improvements of approaching the framework will have a higher impact on the concept development if the students deliberately can apply different types of experiments to their work.

\section{THE TRIPOD APPROACH}

Basically, The Tripod Approach suggests considering the distance to the object as well as the character of the perception. The distance can be divided into three perspectives - material, object and environment - which embrace the multiple levels from fibre to finished product in an overall context. The character of the perception can be either participant or observant $[1,2]$. Originally the material category was defined as 'fabric', but we have experienced that 'material' is more precise. Therefore, we use 'material' in this paper.
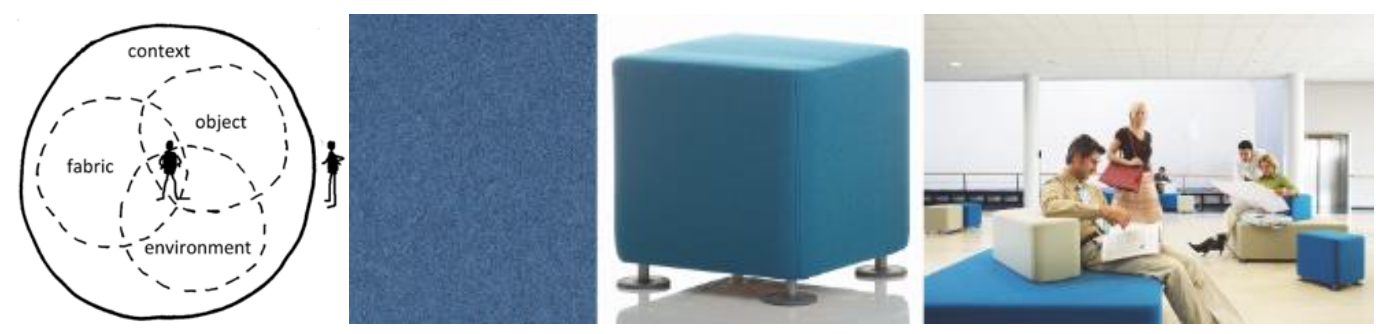

Figure 1. The Tripod Approach [1]

The Tripod Approach applies three distances to either an existing design or a future design concept based on visual perception of material, object and environment. It is possible to use the material category to explore, describe and perceive surface details and materials. In the object perspective, we zoom out to explore and perceive the entire object as well as the surface of the object. Thus, it encourages the viewer to explore, describe and perceive the material as part of an object as well as to perceive the design of the object. Finally, the environment category invites the viewer to explore and perceive the material and the object as part of an environment; that is the application. There may be overlaps between the three categories, and they are all situated within an overall context. The distance perspectives are inspired by the work of the Austrian art historian Alois Riegl [3]. Riegl were interested in the perception of buildings. We have interpreted his theory of perception in relation to design objects, and it allows us to move between the detail and the whole. However, it is crucial to include the multi-sensory aspect in concept development in fashion and textile design. Therefore, The Tripod Approach suggests that the designer approaches the fabric, object and environment from an observant as well as a participant perspective. However, we have experienced that it is more difficult to work with the participant perspective than the observant perspective in the design process. We draw on the Finnish Architect Juhani Pallasmaa's theory about focused or peripheral perception. Like Riegl, Pallasmaa is concerned with the perception of architecture [4]. Where Riegl is interested in the visual distance, Pallasmaa emphasizes the difference between a peripheral visual perception and a focused perception using a multisensory approach. In this context (fashion and textiles), we have interpreted his theory of perception as 
a possibility to move between 'experience' and 'observe'. This is further elaborated in [1,2]. In the following section, we present two examples from the latest concept development course conducted in Autumn 2019.

\section{STUDENT CASES}

We introduce the course asking the students to analyse a jacket using The Tripod Approach to describe material, design and application within an overall context, e.g. style or trend. Following that, each student chooses an overall theme for a design concept. The brief is to express the theme using the three perspectives from both an observant (based on distance) and a participant (experienced) perspective. The students have one week to develop a design concept, including sketches for textile patterns and garments. This is followed by five weeks of working with tools and techniques, developing the ideas and sketches into fabric or form. Finally, there is one week for reflection. During this week, the students refine and sharpen the design concept and finalise the textile series and fashion line-up for presentation. Having a keen interest in ways in which we can further improve The Tripod Approach as a didactic/pedagogical tool for concept development in fashion and textile design, we have documented selected projects from the courses over the years with photos. For this paper, we have chosen two examples from the latest course in 2019 representing two typical approaches to concept development. In this paper, we define them as sensuous-driven or dogma-driven. Having a sensuous-driven starting point, the concept can, for example, be driven by the feeling or mood of a forest, rocks, the ocean, techno etc. Using a dogma-driven starting point, the concept can, for example, be driven by a dogmatic exploration of stripes, everyday textiles, cutting up suits etc.

\subsection{Sensuous driven}

The project 'The Feeling of the Sea' illustrates a sensuous-driven starting point for a design concept. The student worked with the three boards each representing a distance perspective in building the concept for her textile design. The student used photos, materials and keywords. For the material perspective, she used the keywords waves, fragile, powerful and foaming. The keywords for the object perspective are colour, encasing, movement and depth. Finally, the environment is described with the keyword's performance and theatrical. Figure 2 shows the three concept boards of material, object and environment with material experiments and sketches lying around the boards. The result of this concept in terms of design was a series of woven, knitted and printed textiles, which are also shown in figure 2.
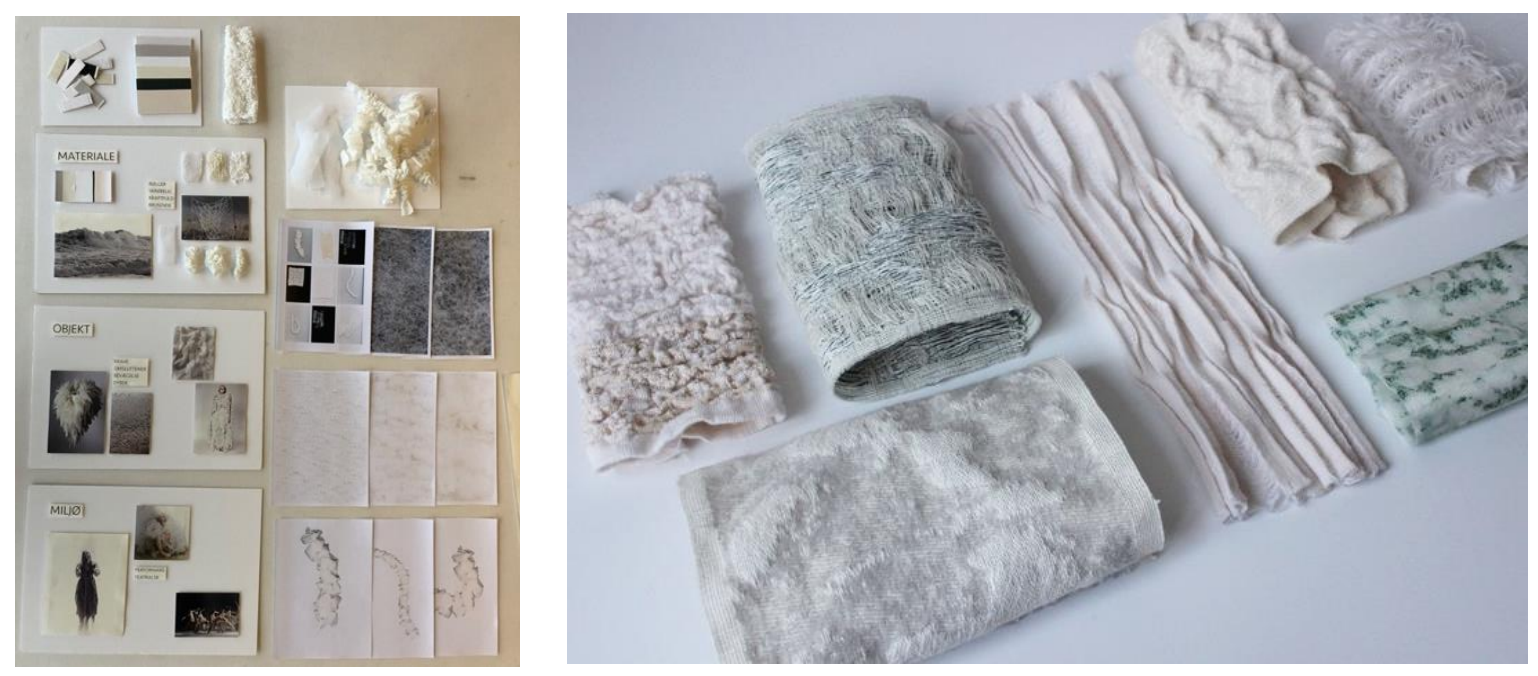

Figure 2. 'The Feeling of the Sea' is an example of a sensuous-driven design process. Left: The three concept boards, material samples and sketches. Right: The series of textiles

\subsection{Dogma-driven}

The project 'The Stripe' demonstrates a dogma-driven starting point for a design concept. In building her concept for textile design, the student worked with three boards each representing a distance perspective. The student used photos, sketches, materials and keywords. For the material perspective she used the keywords mottled, geometrical and repeat. The keywords for the object perspective are circle, rhythmic, texture and focus. Finally, the environment is solely described with materials and 
images. Figure 3 shows the three concept boards of material, object and environment in the development phase and in the final phase. Material experiments and sketches lie around the boards. The result of this concept development in terms of design was a series of woven, knitted and printed textiles for tables, which is shown in figure 4.

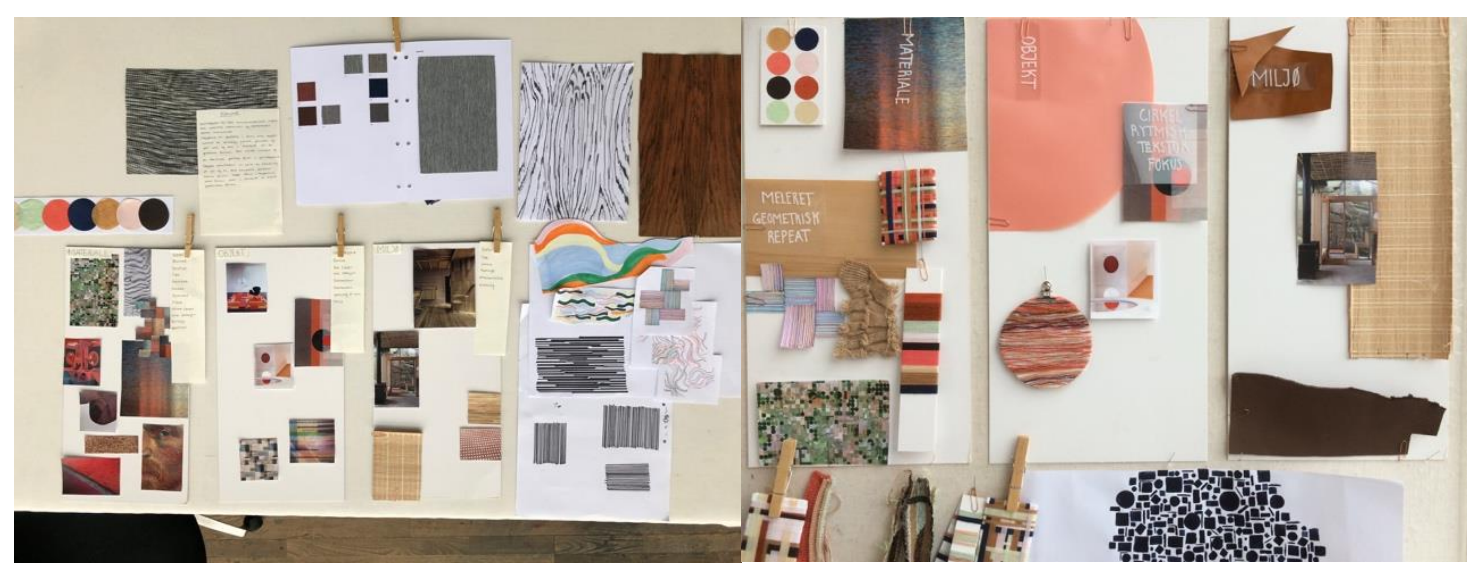

Figure 3. 'The Stripe' is an example of a dogma-driven design process. Left: The three concept boards in an early phase of the process and sketches. Right: The three concept boards in the final stage
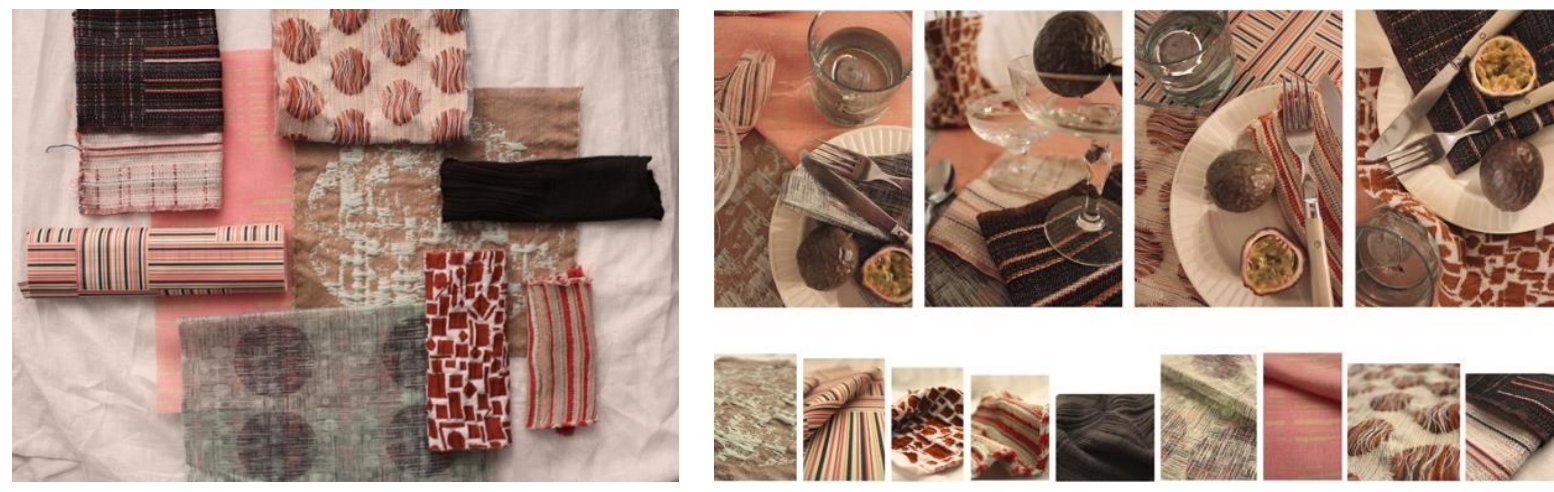

Figure 4. 'The Stripe' is expressed as a series of table textiles. Left: The series of textiles. Right: The series of textiles in an environment (application)

The student includes many different images of stripes on her boards, and she presented the stripe as the central theme of the concept.

\subsection{Teaching experience and reflection}

The Tripod Approach is not a process model. Rather it is a tool for analysis and designing. For designing we understand and use it as a visual project description applicable for delimiting and expressing a design concept through words, images, sketches and materials. Thus, it is a framework that embraces and supports well-proven contents and arguments for concept-building within the field of design. As described in the introduction, fashion and textiles originate from the craft tradition where focus first and foremost is on disciplinary skills. Changing the focus from craft to design, the Tripod Approach offers a framework that allows the fashion and textile design students to go beyond the disciplinary skillsets and yet maintaining an intense focus on prototyping using appropriate tools and techniques.

We ask the students to describe the target for their experiments, and we allow them to adjust the concept during the process. In this way, the concept is further developed in parallel with the fashion and textile design process. This encourages the students to realise that it is possible to refine a concept through reflection-in-action using Schön's well-known and highly respected working concept for practitioners [5].

Analysing the students work and discussing ways in which to improve the didactic and pedagogical approach, we have identified three issues relevant for the discussion in this paper. First, our review shows that whereas the three perspectives of distance are usually very clearly elaborated, the overall 
context is more implicit and even invisible in some projects. During supervision, we have noticed that several students work with a 'secret' inspiration board. It is secret in the sense that The Tripod Approach in the current version does not encourage students to include considerations regarding their overall inspiration. Secondly, we have observed that there are several entrance points to a strong concept development. The examples above are a sensuous-driven and a dogma-driven approach to concept development. These approaches are recurring entrance points that usually lead to strong design concepts. Finally, we have experienced that while it is very straight-forward to introduce and work with the observant perspectives in the concept development process, the students find it more difficult to apply a clear approach to the participant perspectives of material, object and environment.

\section{ADDRESSING THE CONCERNS}

In this section, we suggest three areas where The Tripod Approach can be further developed as a didactic and pedagogical framework for concept development in fashion and textile design.

\subsection{The overall context and the 'secret' inspiration board}

While the three perspectives material, object and environment are often thoroughly elaborated in the students' concepts, the overall context is more implicit and maybe even taken for granted. As a result, the perspectives on material, object and environment often dominate the way the concept is presented. It does not mean that the overall context does not exist, but it is underplayed in the visual presentation and verbal communication of the concept. Additionally, it is highly problematic that the students hide their inspiration material. They do this simply because they do not know how to include it in the given framework of three perspectives in an overall context. Therefore, we propose to add a fourth board considering the overall context. This board can include inspiration material, trend analysis, problem statement, societal and political considerations and other arguments for the design concept. It will be interesting to follow the students' work with the context board in future courses. What kind of insights will it bring to the concept development?

\subsection{Strong concept development}

The student examples above demonstrate that it is possible to develop strong concepts from a sensuousdriven or a dogma-driven starting point. In our teaching, we have also noticed that some students tend to skip the concept development in favour of concrete product decisions, e.g. development of sportswear in classic sportswear materials for a sport environment. Where the sensuous- or dogma-driven approach has a divergent impact on the process, the product-driven approach is simply focused on the end-product rather an inspiring and convergent process. Therefore, the product-driven projects suffer from a too short or missing divergent phase before making decisions on the concept. Thus, having discovered how much influence the entrance point to concept development means for the concept development, we suggest emphasising this in the introduction to the students. Here we can draw on existent design methodology about divergent and convergent thinking as expressed in for example the Double Diamond process model [6].

\subsection{The participant versus the observant perspective}

In our introduction of the observant and participant perspectives, we apply Riegl's theory of distance as an observant, visual approach, and Pallasmaa's theory as a participatory felt approach to concept development. In our review and from several oral student presentations, we have learned that while the observant perspective is straightforward and easy to apply to the concept development, it is much harder to apply a participating and 'felt' perspective. One reason for this may be that the observant perspective is strongly connected to the visual distance to the fabric or the garment. It is very concrete when it comes to visualising and sketching on the material, the object and the environment. The participant perspective is defined as 'felt'. 'Felt' is not as concrete as 'visual distance' and thus harder to challenge and visualise in a concept. A suggestion might be to introduce the participant perspective as 'experienced'. We need to stress this in our teaching didactically, emphasizing it in our introductions and supervision.

\section{EXPERIMENTS AS A CORE DRIVER FOR CONCEPT DEVELOPMENT}

The central aim of this paper is to discuss ways in which the pedagogical and didactic approach to the Tripod Approach can be refined. Therefore, we conducted a review of student concepts from eight courses exemplified by two projects in this paper. We have identified three issues for improvement: 
emphasising the overall context, encouraging to use entrance points to concept development that support a convergent/divergent thinking and finally, understanding the participatory perspective of the framework as 'experienced' instead of 'felt'. Basically, we use The Tripod Approach as a framework to encourage the fashion and textile students to combine concept development with design experiments in the workshops. This means that continuous design experiments play a central role in the students' learning process. Likewise, our suggestions for improving The Tripod Approach will lead to further experimentation.

The American philosopher and Professor Donald Schön was concerned with experiments and proposed to apply three different types of experiments to practice depending on the purpose of experimenting [5]. These are exploratory testing, move testing and hypothesis testing experiments. Where exploratory experiments are undertaken to see what follows, a move testing experiment is conducted as an action to produce an intended change. Finally, a hypothesis testing experiment is a process of eliminating competing hypotheses. Hence, each type of experiment has a different purpose [5]. In a previous study about experiments in practice-based design research, we have described exploratory experiments as initiating or driving experiments, move testing experiments as experiments that mature and stabilise, and finally hypothesis testing experiments as finalising experiments [7].

We have observed that when the students are in the initial phase of concept development, they conduct a lot of 'random' and exploratory experiments simply to see what happens and to test or challenge their ideas for a concept. Secondly, we can see a more determined experimentation in the phase where they strengthen the concept in parallel with the design work. This is like move testing experiments since the aim is to produce an intended change and not only try things out. We have also observed that before the final presentation of concept and design work, all students without exception refine the boards to express the concept in the most precise way. They perform a discrimination, and it may be compared to hypothesis testing experiments. It makes sense to improve the introduction to the experimental phase of the course as it goes hand in hand with the concept development.

\section{THE OVERALL CONTEXT}

We want to finish the paper by addressing the importance of a strong fashion and textile design profession. It is important that fashion and textile designers can contribute to the development of relevant and detailed design concepts. Not only because of employability and the yearly turnover in the companies. It is highly important that fashion and textile designers can contribute to the sustainable development of the industry and its enterprises. Therefore, it makes sense to further train the students to use design as a driver for sustainable development. The Tripod Approach has proven to be a relatively fast way to lay a strong, accessible and communicative ground for strong design concepts within fashion and textile. Having in mind that ideation and concept development are under time pressure in an industry mainly focusing on the economic bottom line, we find it valuable to refine and sharpen approaches that link deep professionalism with industry requests.

\section{REFERENCES}

[1] Bang, A. Emotional Value of Applied Textiles - Dialogue-oriented and participatory approaches to textile design, 2013 (Kolding: Kolding School of Design), PhD-Thesis.

[2] Bang A. The Tripod Approach: A Systematic and Structured Framework to Designing Applied Textiles. In: Brasset J., Hekkert P., Ludden G., Malpass M. \& McDonnell J. (eds.). Proceedings of the $8^{\text {th }}$ International Design and Emotion Conference: Out of Control, London, UK, 2012

[3] Riegl, A. Senromersk Kunstindustri, 1901. In: Bek, L. \& Oxvig, H. (eds.) (1997), Rumanalyser, 1997 (pp. 45-68). (Aarhus: Fonden til udgivelse af Arkitekturtidsskrift B).

[4] Pallasmaa, J. The eyes of the Skin. Architecture and the Senses, 2005. (Chichester: John Wiley \& Sons Ltd).

[5] The Design Council, https://www.designcouncil.org.uk/news-opinion/what-frameworkinnovation-design-councils-evolved-double-diamond [Accessed on 2020, 5 June]

[6] Schön, D. The Reflective Practitioner. How Professionals Think in Action, 1983. (London: Ashgate).

[7] Bang A. \& Eriksen M. Experiments All the Way in Programmatic Design Research, ArtifactThe Journal of Design Practice, 2020, Vol 6, No 1-2, 2020, pp. 8.1-8.20 (re-publishing). 